CARROLL, Lewis. Alice através do espelho (e o que ela encontrou do outro lado). Tradução de Jorge Furtado e Liziane Kugland. Ilustrações de Edu Oliveira. São Paulo: Companhia das Letrinhas, 2017. $200 \mathrm{p}$.

ISBN: 9788574067803

\title{
LEWIS CARROLL E O SONHO DENTRO DO SONHO
}

\section{LEWIS CARROLL AND THE DREAM WITHIN A DREAM}

\author{
José Francisco Botelho ${ }^{1}$
}

Quando uma obra estrangeira é objeto de múltiplas traduções, o olho crítico saberá encontrar aí, pelo menos, dois indícios possíveis: existe no texto original uma correspondente multiplicidade de sentidos, que jamais terminam de serem expressos e que voltam sempre a interpelar leitores, tradutores e críticos, reproduzindo-se como espelhos que se defrontam; além disso, é de se pensar também que haja algo na língua e na cultura de chegada que demanda a reiterada aparição de um livro, em renovadas tonalidades e dicções. É o que acontece com a obra de Lewis Carroll, traduzida diversas vezes em português. Through the Looking Glass - texto objeto desta resenha - instigou ao menos duas traduções no Brasil nos últimos oito anos. Uma delas foi realizada por Maria Luiza X. de A. Borges e publicada pela Zahar em 2010. Outra, assinada por Jorge Furtado e Liziane Kugland, saiu pela Companhia das Letrinhas em 2012 e foi reeditada em 2017 - sinal de que existe um interesse contínuo pela obra de Carroll entre nossos leitores. A tradução de Furtado e Kugland mira no público infantil e trata de envolver as crianças brasileiras de hoje, assim como a obra original visava as crianças da Inglaterra vitoriana. Para isso, recorre ao saboroso estratagema de recriar os trocadilhos e enleios lógicos de Carroll por meio das parlendas brasileiras - procedimento que recupera a vivacidade do texto, ao mesmo tempo aproximando-o do público atual e devolvendo-lhe algo semelhante ao efeito que provocava em sua própria época. O que enseja esta resenha, contudo, não são questões tradutórias, mas um paradoxo narrativo, presente na obra de Carroll e associado a outros textos de múltiplos períodos, que sempre me fascinou enquanto leitor, escritor e tradutor: o sonho dentro do sonho.

\footnotetext{
${ }^{1}$ Tradutor e doutorando do Programa de Pós-graduação em Letras da Universidade Federal do Rio Grande do Sul.
} 
A literatura, escreveu Borges, é um sonho dirigido; e a própria existência humana, em reiteradas páginas, foi apresentada como experiência onírica. A contaminação da vigília pela maré às vezes ameaçadora do sonho é um recurso antigo na ficção e na poesia. Lembremos do mito grego: muitas vezes os deuses usaram as sombras da inconsciência como forma de guiar ou desencaminhar os mortais. No Livro II da Ilíada, Zeus envia a Agamenon um sonho alado, maligno e enganador, para convencê-lo a atacar Troia de forma temerária; e muitas almas gregas desceram ao Hades porque o rei foi ludibriado enquanto dormia. Em 1611, Shakespeare colocou na boca de Próspero, em A Tempestade, certas linhas que seriam parafraseadas séculos depois em $O$ Falcão Maltês, clássico noir de John Houston: "We are such stuff as dreams are made on, and our little life is rounded with a sleep" ("Somos feitos da mesma matéria dos sonhos, e nossa pequena vida se completa entre o dormir e o despertar"). Cerca de vinte anos após a estreia d'A Tempestade, a mesma ideia ecoaria do outro lado do Canal da Mancha, na inesquecível obra de Calderón de La Barca, La vida es sueño. Preso entre as ilusões da vigília e as fantasias verossímeis do mundo onírico, o príncipe Segismundo nos deixou aquele monólogo que jamais será suficientemente citado:

\footnotetext{
¿Qué es la vida? Un frenesi.

¿Qué es la vida? Una ilusión, una sombra, una ficción, y el mayor bien es pequeño: que toda la vida es sueño, y los sueños, sueños son.
}

Todos esses exemplos tratam o sonho como metáfora da vida, ou a vida como província do sonho; na segunda metade do século XIX, uma outra volta no parafuso foi efetuada pelo Reverendo Charles Lutwidge Dodgson, professor de matemática em Christ Church, Oxford, fotógrafo diletante, aficionado por enigmas e trocadilhos, e mais conhecido pelo nom de plume Lewis Carroll. Hoje todos sabem, naturalmente, que sua imortal personagem, Alice, saiu certo dia a perseguir um coelho branco, enveredou por uma região de dimensões cambiantes e população fantasticamente híbrida, para então descobrir-se de volta à "morosa realidade", bocejando na relva soprada pelo vento. Publicado em 1865, Alice no País das Maravilhas despertou o fervor imediato de batalhões de leitores (entre eles, segundo reza a lenda, a Rainha Vitória); mas é sua vertiginosa e perturbadora continuação, Alice Através do Espelho, publicada em 1871, que interessa a este artigo.

A história da literatura oferece estranhas e reveladoras simetrias: de certa forma, o destino póstumo de Lewis Carroll é um reflexo invertido de Jonathan Swift. No século XVIII, 
Swift escreveu As Aventuras de Gulliver, livro para adultos amargos, cujo objetivo era fustigar com mordacidade toda a raça humana - mas que agora é lembrado como uma história para crianças. Em Alice Através do Espelho, Carroll escreveu um livro declaradamente voltado à fantasia de meninas em idade pré-escolar - mas que hoje é lido principalmente por adultos. Se algo desviou essas obras de seu sentido original, foram precisamente suas virtudes: o livro de Swift encanta pela sucessão sempre surpreendente de peripécias e perigos, fazendo-nos esquecer a moral pessimista do autor; o livro de Carroll intriga e estonteia pelas piruetas lógicas e a ousadia da linguagem, deixando em segundo plano o caráter propriamente aventuresco da narrativa. Essas inversões e espelhamentos compõem, talvez, um sentido secreto e maior.

Ao fim da primeira aventura de Alice, somos deixados com a impressão de que as andanças da protagonista em um mundo governado por naipes e povoado por animais falantes não passou de um sonho; na continuação da história, o recurso onírico torna-se mais complexo, dando origem a um motivo específico na história das narrativas universais, cujas propagações foram abundantes na literatura do século XX e repercutem até em recentes sucessos da televisão. Não darei um resumo do livro: basta saber que, exatos seis meses após a primeira aventura, Alice atravessa o espelho de sua casa e começa a desbravar uma nova região feérica. Se a estética do baralho dominava o País das Maravilhas, a Terra Além do Espelho segue o esquema existencial de um grande tabuleiro de xadrez. Os recônditos desse labirinto metafísico são mais inquietantes e cerebrais que a viagem anterior - em diversas passagens de Finnegans Wake, James Joyce deixou claro seu débito à segunda jornada de Alice. Mas o que nos interessa, no momento, é certa passagem do capítulo 4, em que Alice se depara com o Rei Vermelho adormecido em um bosque. Segue-se um dos diálogos mais importantes na literatura dos últimos duzentos anos.

\footnotetext{
"Ele está dormindo agora", disse Tweedledee. "E você sabe com que ele está sonhando?"

Alice respondeu:

"Isso ninguém pode adivinhar."

"Ora, está sonhando com você!" Tweedledee exclamou, batendo as mãos em triunfo. "E se ele parar de sonhar com você, onde você acha que vai parar?"

"Onde eu estou agora, é claro," disse Alice.

"Não mesmo!" Tweetledee retrucou, com desprezo. "Você iria parar em lugar nenhum. (...) Porque você é apenas uma das partículas do sonho. No fundo você sabe que você não é real."

"Eu sou real!" disse Alice, e começou a chorar.
}

Alice está sonhando com o Rei Vermelho, que está sonhando com Alice, que está sonhando com o Rei Vermelho, que está sonhando com Alice... A proeza de Carroll nessa 
passagem é um dos mais perfeitos exemplos literários do que André Gide chamava mise en abîme: um objeto que contém a si mesmo, numa regressão ao infinito, como dois espelhos postos frente a frente. Algum leitor arguto terá, a estas alturas, pensado em Borges: xequemate. "As Ruínas Circulares" conta a história de um mago persa que decide "sonhar um homem" e "impô-lo à realidade"; nas linhas finais da história, o personagem compreende, “com alívio, com horror, com humilhação, que ele também era uma aparência, que outro o estava sonhando". Publicado como parte de Ficções, em 1941, "As Ruínas Circulares" é diretamente inspirada na obra de Carroll: prova disso é a epígrafe do conto, extraída da passagem que reproduzi acima.

O Sonho dentro do Sonho é um dos paradoxos narrativos mais férteis, reveladores e profundos na ficção literária. Suas possibilidades narrativas talvez sejam infinitas, como o espelho refletido no espelho; suas repercussões mentais nos fazem transitar pela Caverna de Platão, pelas aporias dos céticos antigos, pela dúvida universal de David Hume, em busca de uma resposta para a pergunta feita por Alice nas linhas finais do romance de Carroll: "Vamos considerar agora: quem está sonhando, de verdade?" Os admiradores de David Lynch certamente acharão algo de familiar nessas palavras: há uma paráfrase delas em uma cena crucial de Twin Peaks: O Retorno. O agente Gordon Cole, interpretado pelo próprio Lynch, sonha estar na mesa de uma cafeteria, conversando com Monica Bellucci. As palavras por ela pronunciadas contêm a cifra secreta desta série aparentemente indecifrável: "Somos como um homem que sonha, e vive dentro do sonho. Mas quem está sonhando?”

\section{BIBLIOGRAFIA}

BORGES, Jorge Luis. Ficciones. São Paulo: Debolsillo, 2011.

CARROL, Lewis. The complete illustrated works of Lewis Carroll. Hertfordshire: Wordsworth, 2006.

CARROLL, Lewis. Through the looking-glass and what Alice found there. North Charleston: Seahorse Classics, CreateSpace Independent Publishing Platform, 2016.

DE LA BARCA, Calderón. La vida es sueño. s.l.: Penguin Clásicos, 2015.

HOMER. The Iliad. Trad. Robert Fagles. Harmondsworth: Penguin Classics, 1999.

SHAKESPEARE, William. The tempest. London: The Arden Shakespeare, 2011.

SWIFT, Jonathan. Gulliver's travels. London: Penguin Classics, 2003. 
JOYCE, James. Dublinenses. Tradução de Caetano W. Galindo. São Paulo, Companhia das Letras, 2018. 280p.

ISBN 9788582850770

RUFFATTO, Luiz. A cidade dorme. São Paulo: Companhia das Letras, 2018. 128 p. ISBN 9788535926644 